\title{
POLÍTICAS TRIBUTÁRIAS MUNICIPAIS DE INCENTIVOS FISCAIS: EXTRAFISCALIDADE E O DIREITO HUMANO FUNDAMENTAL AO MEIO AMBIENTE SUSTENTÁVEL - INSTRUMENTALIZAÇÃO PARA O DESENVOLVIMENTO E PARA A INCLUSÃO SOCIAL ${ }^{1}$
}

\author{
MUNICIPAL TAX POLICY OF TAX INCENTIVES: \\ STIMULATING FUNCTION AND FUNDAMENTAL HUMAN RIGHT TO \\ SUSTAINABLE ENVIRONMENT - INSTRUMENTALIZATION DEVELOPMENT \\ AND SOCIAL INCLUSION
}

Hugo Thamir Rodrigues ${ }^{2}$

Eli Carla da Silva Muller ${ }^{3}$

\begin{abstract}
RESUMO - O tema do comprometimento do meio ambiente, a par de ser por demais debatido, não pode ser abandonado, em função dos pequenos avanços em relação à reversão do ciclo de esgotamento do ecossistema. $O$ trabalho busca, nesse sentido, apresentar a intervenção estatal através de políticas públicas tributárias extrafiscais de concessão de benefícios fiscais, no âmbito municipal, como instrumento de estímulo a comportamentos não poluentes dos entes econômicos privados. A Constituição Federal em seu art. 23, VI, estabelece como competência comum aos entes federados a proteção ao meio ambiente, de onde se retira que é dado ao município o poder-dever de 'concretizar' a Constituição por meio de políticas públicas que viabilizem o direito humano fundamental ao meio ambiente sustentável.
\end{abstract}

PALAVRAS-CHAVE - Benefícios fiscais. Direito fundamental ao meio ambiente. Municípios. Politicas públicas tributárias.

ABSTRACT - The theme of compromising the environment, alongside be debated by others, can not be abandoned, due to small improvements over the reversal depletion cycle of the ecosystem. The job search in this sense, the present state intervention through public policy tax the stimulating function granting tax benefits at the local level, as an instrument to stimulate clean behavior of private economic entities. The Federal Constitution in its article 23, $\mathrm{VI}$, establishes competence as common to federal agencies to protect the environment from which it was deduced that the municipality is given the power

\footnotetext{
Artigo vinculado ao projeto de pesquisa intitulado: Tributação e mudança social em âmbito municipal: possibilidades da utilização de normas tributárias indutoras a partir de uma leitura sistemática da Constitução Federal. Vinculação, também, ao grupo de pesquisa, pertencente ao PPGD da UNISC, intitulado: Direito Tributário e Políticas Públicas de Desenvolvimento e inclusão social. Órgão financiador: UNISC.

2 Doutor em Direito pela Universidade Federal de Santa Catarina (UFSC), professor do PPGD/Doutorado e Mestrado da Universidade de Santa Cruz do Sul (UNISC), professor, nos cursos de graduação em Direito da UNISC e da Universidade de Passo Fundo (UPF). Líder do grupo de pesquisa, do PPGD da UNISC, intitulado: Direito Tributário e Políticas Públicas de Desenvolvimento e Inclusão Social. E.mail: hugo@unisc.br.

Advogada, mestranda do Programa de Pós Graduação em Direito da Universidade de Santa Cruz do Sul RS, na linha de Políticas Públicas de Inclusão Social. Participante do grupo de pesquisa do PPGD da UNISC intitulado: Direito Tributário e Políticas Públicas de Desenvolvimento e Inclusão Social. E.mail: elicarla@yahoo.com.br
} 
and duty to 'realize' the Constitution by public policies that allow the fundamental human right to environment sustainable.

KEYWORDS - Tax benefits. Fundamental right to the environment. Municipalities. Public tax policies.

\section{CONSIDERAÇÕES INICIAIS}

Dentro do contexto da crise global de degradação do planeta, o Estado não pode abster-se de se posicionar acerca das questões que envolvem a própria sobrevivência da humanidade. O combate ao sistema de degradação do meio ambiente deve ser uma preocupação universal. A proteção ambiental abrange a preservação de toda a natureza, numa acepção ampla, envolvendo todos os elementos essenciais a vida humana e ao equilíbrio ecológico, em função do entendimento de que a qualidade de vida é uma forma de direito fundamental da pessoa humana. A manutenção das qualidades ambientais que são necessárias à própria vida, numa perspectiva que contemple essa "nova projeção do direito à vida", é o que se pretende ver tutelado, atendido e amparado pelo ordenamento jurídico, enquanto guardião do interesse público (SILVA, 2007).

Destacam-se, nesse aspecto, os instrumentos tributários e fiscais, como elementos otimizadores dessa atuação, dentro da necessidade de se realizar o princípio basilar do ordenamento jurídico brasileiro: a dignidade da pessoa humana. É ressaltada a importância da utilização extrafiscal dos tributos, numa ótima relação entre o dever de a tributação também realizar o objetivo maior da dignidade humana, implementada através da qualidade de vida. Apresentam-se os incentivos fiscais como a mais efetiva conjugação da tributação com a preservação ambiental, com base em doutrinadores clássicos e modernos, concluindo-se que são esses benefícios os mecanismos que melhor se coadunam com os objetivos da Constituição da República Federativa do Brasil de 1988 (CF).

O tema se faz relevante por tratar de uma das questões mais urgentes que afetam diretamente a qualidade de vida e a própria existência digna no planeta, o risco de colapso do ambiente em que vivemos. A preocupação 
internacional e global com o tema ressalta a sua pertinência. Ao mesmo tempo, o Direito Tributário é uma das facetas mais eficientes da atuação estatal. Além de ter sua fundamentação na solidariedade social, revela-se um dos mais importantes instrumentos do Estado na condução do comportamento dos entes econômicos privados, senão o mais eficiente. $A$ intersecção dessas duas áreas do Direito revela-se por demais produtiva e rica, para que aflorem atitudes mais responsáveis com relação à atividade produtiva. O desenvolvimento econômico e a sustentabilidade têm aí seu melhor elo, primando pela dignidade humana como fim último de proteção.

A CF impôs ao Estado brasileiro o dever de intervir na economia para assegurar a proteção ao meio ambiente, no contexto de uma política pública econômico-fiscal. A efetiva melhoria do meio ambiente depende, substancialmente, do exercício do poder-dever político do Estado, através da intervenção na atividade econômica, vez que a questão ambiental está com esta intimamente associada. A CF, no seu artigo 170, deixa clara a opção do legislador por uma ordem econômica intervencionista, e o Estado, se posicionado na negociação entre os diversos interesses individuais e coletivos dos diferentes agentes econômicos, deve nortear sua atuação pela defesa do meio ambiente.

Todo desenvolvimento, assim, tem que se acomodar para estar em conformidade com a proteção ambiental e a tutela dos demais direitos fundamentais. Como leciona Amaral (2007, p. 37), "[...] a proteção ambiental é condição sine qua non para se realizar os objetivos constitucionais [...]".

De lembrar, enfim, o fato de os Municípios serem entes estatais (republicanos e federados), cabendo-Ihes a obrigação de participar, nos termos da CF, no teor de seus artigos 30, I, II, VII, VIII e 23, I, III, VI, VII, XI, de políticas públicas ambientais, quer isoladas, quer cooperadas (Rodrigues; Freitas, 2009), que permitam o desenvolvimento ${ }^{4}$ de seus munícipes quanto à melhoria da qualidade de vida através de ganhos à saúde (mental e física).

\section{A NECESSÁRIA PROTEÇÃo DO MEIO AMBIENTE E DA DIGNIDADE}

4 O termo desenvolvimento é aqui utilizado no sentido que Ihe empresta Grau (2002), qual seja aquele que é medido pelo índice de variação da qualidade de vida da população. 


\section{HUMANA}

O reconhecimento e a proteção dos direitos do homem estão nas bases das constituições democráticas modernas (LEAL, 2003). Nesse sentido, também a CF, no art. 225, trouxe inúmeras inovações ao ordenamento jurídico brasileiro referentes ao direito fundamental ao meio ambiente saudável. De início elevou o meio ambiente à condição de bem do uso comum do povo, o que confere a todos o direito ao meio ambiente ecologicamente equilibrado.

Todavia, é atribuída a toda a coletividade, o dever de zelar por sua defesa e preservação para as presentes e as futuras gerações. Conseqüentemente, a Constituição intentou assegurar a todos um desenvolvimento econômico e social sustentável, coibindo o uso indiscriminado e predatório dos recursos naturais. Ou seja, o art. 225 não estabelece apenas um direito subjetivo, mas também uma imposição objetiva, um mandamento constitucional que deve ser cumprido pelo Poder Público e, também, principalmente, pelos responsáveis pelas atividades degradantes da qualidade e do equilíbrio ambiental. Depreende-se que o legislador constitucional buscou inserir um conteúdo humano e social no conceito de meio ambiente, que não se reduz aos elementos naturais (ar, água, terra etc.). Consoante Antunes, o meio ambiente deve ser compreendido como "[...] o conjunto das condições de existência humana, que integra e influencia o relacionamento entre homens, sua saúde e seu desenvolvimento [...]" (CIRINO; BASSOLI, 2008). Considerando-o como direito fundamental da pessoa humana e como um princípio constitucional, Milaré justifica o valor do direito a um ambiente ecologicamente equilibrado. Para o jurista, o reconhecimento do direito a um meio ambiente sadio "[...] configura-se, na verdade, como extensão do direito à vida, quer sob o enfoque da própria existência física e saúde dos seres humanos, quer quanto ao aspecto da dignidade desta existência - a qualidade de vida -, que faz com que valha a pena viver [...]". Dada a importância do tema, o autor assevera que o principio do meio ambiente ecologicamente equilibrado "[...] é, sem dúvida, o princípio transcendental de todo o ordenamento jurídico ambiental, ostentando, a nosso ver, o status de verdadeira cláusula pétrea [...]" (FIGUEIREDO, 2005, p. 570). 
Corroborando este entendimento, Silva (2007, p.70):

[...] o que é importante - escrevemos de outra feita - é que se tenha consciência de que o direito a vida como matriz de todos os demais direitos fundamentais do homem é que há de orientar todas as formas e atuação no campo da tutela do maio ambiente [...] a tutela da qualidade do meio ambiente é instrumental no sentido de que, através dela, o que se protege é um valor maior: qualidade de vida.

Destacam-se nessas afirmações, que a vida, sendo o bem maior a ser protegido, vem ao encontro do entendimento de que a proteção ao meio ambiente, conforme positivada na CF tem o homem e sua vida - e a qualidade de vida a que se refere o autor, bem pode ser considerada como sinônimo de dignidade - como objetos principais de proteção. A dignidade humana, conforme já visto, é o cerne de todo o comprometimento do Estado e da sociedade na preservação ambiental e na sustentabilidade. Para Figueiredo (2005), o direito ao meio ambiente equilibrado, é um direito digno de proteção tão especial quanto o direito à vida humana, por estar com ela intimamente relacionado. Trata o direito humano fundamental como um princípio ambiental, na medida em que dele depende a qualidade de vida.

No final do século XX é que se consubstanciam como produto de uma reflexão mundial sobre o desenvolvimento humano, os direitos chamados de terceira dimensão (ou geração). Estes direitos têm como fundamento o valor da fraternidade e são carregados de um grande conteúdo de humanismo e universalidade. Não se destinam especificamente à proteção dos interesses de um indivíduo, de um grupo ou de um determinado Estado, mas ao próprio gênero humano. $\mathrm{E}$ o direito ao meio ambiente está classificado como um direito fundamental de terceira dimensão.

O direito ao meio ambiente foi cunhado pela Conferência das Nações Unidas sobre o Ambiente Humano de 1972 (Princípio 1), (5) reafirmado pela Declaração do Rio sobre Meio Ambiente e Desenvolvimento de 1992 (Princípio 1) (6) e pela Carta da Terra de 1997 (Princípio 4), (7) Estas declarações proclamaram inúmeros princípios fundamentais de proteção ambiental que acabaram influenciando diretamente o conteúdo de muitas constituições modernas e a elaboração do capítulo sobre o meio ambiente da Constituição brasileira (SILVA, 2007, p. 60-64). 
Oliveira (2007, p. 9) ocupa-se com o tema, elegendo o direito ambiental como um direito de superposição aos direitos pré-existentes. Numa perspectiva fundamental dos direitos humanos, colaciona que a deterioração ambiental pode chegar a impedir o gozo de outros direitos fundamentais já reconhecidos.

Com relação ao desenvolvimento sustentável, Amaral (2007, p. 33) assim o conceitua:

O desenvolvimento sustentável é aquele que assegura as necessidades da presente geração sem comprometer a capacidade das gerações futuras de resolver suas próprias necessidades. A presente geração tem o dever de deixar para as futuras gerações um meio ambiente igual ou melhor do que aquele que herdou da geração anterior.

O conceito associa-se à contribuição de Milaré, para quem desenvolvimento sustentável "[...] é aquele que propugna por um crescimento econômico qualitativo, única forma de melhorar a qualidade da vida humana dentro dos limites da capacidade se suporte dos ecossistemas [...]" (FIGUEIREDO, 2005, p 572).

Segundo Silva (2007, p. 59), o conceito de desenvolvimento sustentável nasceu durante a Conferência das Nações Unidas sobre Direitos Humanos e Meio Ambiente em 1972. Esse novo direito fundamental foi reconhecido pela Declaração do Meio Ambiente, fruto dessa conferência mundial, e confirmado na conferencia das nações unidas sobre meio ambiente e desenvolvimento em 1992 que ocorreu no Brasil. Realçou-se nesse momento o papel central dos seres humanos como objeto das preocupações de um projeto de desenvolvimento sustentável. Em conformidade, a Declaração do Meio Ambiente:

Os dois aspectos do meio ambiente, o natural e o artificial, são essenciais para o bem-estar do homem, e para que ele goze de todos os direitos humanos fundamentais, inclusive o direito à vida mesma. [...] a proteção e a melhora do meio ambiente é uma questão fundamental que afeta o bem estar dos povos e o desenvolvimento econômico do mundo inteiro; é um desejo urgente dos povos de todo o mundo e um dever de todos os governos.

[...] a defesa e a melhoria do meio ambiente para as gerações presentes e futuras converteu-se num objetivo imperioso para a Humanidade e deverá ser perseguido, ao mesmo tempo em que o são as metas fundamentais já estabelecidas da paz e do desenvolvimento econômico e social em todo o mundo [...]. (grifo nosso) 
Ainda vinculado aos valores da dignidade humana, o direito ambiental, considerado associado intimamente com os valores constitucionais da livre iniciativa e sociais do trabalho, tem a incumbência de direcionar a harmonização da relação entre a ordem econômica e a defesa do meio ambiente. Contudo, para assegurar esse direito, é necessário que se efetive o poder-dever do Estado na adoção de políticas públicas adequadas a proteção ambiental e que se resgate do dever solidário da coletividade.

A CF permite, no art. 174, que o Estado intervenha na área econômica a fim de realizar os princípios que orientam a ordem jurídico-econômica. Desta feita, analisando o art. 170, VI, verifica-se que há autorização constitucional para a intervenção do Estado sobre a economia, também para executar políticas públicas ambientais que tenham por fim proteger o meio ambiente e induzir condutas dos agentes econômicos em relação à obrigação de que seja efetivamente implementada no Brasil à idéia da sustentabilidade ambiental.

A nova perspectiva do exercício da função ambiental é exatamente a harmonização dos princípios da ordem econômica e social e a dignidade humana, princípio constitucional destacado como fundamento da República Federativa do Brasil, no artigo 1ํㅡㄹ inciso III da CF. Este é o alicerce que justifica um emprego mais positivo dos instrumentos econômicos em prol do meio ambiente (TUPIASSU, 2006).

Para Amaral, compreender o princípio do desenvolvimento sustentável significa ter em mente que é necessário o estímulo a medidas efetivas de proteção ambiental, e que o instrumento para tal passa pela adoção de estratégias econômicas e fiscais, que tenham força para alterar os comportamentos indesejáveis.

A CF institui:

Art. 225. Todos têm direito ao meio ambiente ecologicamente equilibrado, bem de uso comum do povo e essencial à sadia qualidade de vida, impondo-se ao poder público e à coletividade 0 dever de defendê-lo e preservá-lo para as presentes e futuras gerações.

Esse dispositivo é dividido em quatro partes por Fiorillo (2006): a primeira trata da expressão "todos", que caracteriza esse direito como difuso; a 
segunda é relacionada à compreensão de bem ambiental como sendo de uso comum do povo, ou seja, não é público nem privado, mas cabe ao poder público gerenciá-lo em benefício do povo; a terceira diz com a finalidade do direito ambiental, estabelecendo que o bem ambiental é aquele essencial à sadia qualidade de vida; por fim, a quarta parte estabelece que 0 bem ambiental deve ser resguardado no interesse das presentes e futuras gerações.

Assim, o direito ao ambiente é de cada pessoa, mas não somente dela, sendo, portanto, transindividual. Nesse sentido, manifestou-se o Supremo Tribunal Federal, através de voto proferido pelo Ministro Celso de Mello na Medida Cautelar da Ação Direta de Inconstitucionalidade número $3540 .{ }^{5}$

Vale relevar, ainda, o posicionamento de Tôrres (2005, p. 111):

Não há, no art. 225, só um direito subjetivo reconhecido, mas uma determinação objetiva, e não programática, ao 'Poder Público', em todas as suas dimensões, sob a forma de autêntico mandamento constitucional, a ser respeitado em todos os seus termos, mormente pelos responsáveis por atividades diretamente vinculadas com afetação a qualquer espécie de bem ambiental.

A atividade econômica deve ser repensada, de forma a harmonizar-se com a necessidade de melhoria ambiental; e é nessa conjuntura que se localiza o papel do Estado, com seu poder político, na implementação de políticas públicas de mediação entre os interesses econômicos e os interesses individuais e coletivos. E a defesa do meio ambiente, segundo Modé (2004), é um dos princípios norteadores da atividade intervencionista do Estado.

Nesse contexto, Machado entende que o Poder Público passou a figurar não como proprietário de bens ambientais, mas como um gestor que administra bens que não são dele. Esse posicionamento impõe ao Poder Público o dever

\footnotetext{
${ }^{5}$ Trata-se, consoante já o proclamou o Supremo Tribunal Federal (RTJ 158/205-206, Rel. Min. CELSO DE MELLO), com apoio em douta lição expendida por CELSO LAFER ("A reconstrução dos Direitos Humanos", p. 131/132, 1988, Companhia das Letras), de um típico direito de terceira geração (ou de novíssima dimensão), que assiste, de modo subjetivamente indeterminado, a todo o gênero humano, circunstância essa que justifica a especial obrigação que incumbe ao Estado e à própria coletividade (PAULO AFFONSO LEME MACHADO, "Direito Ambiental Brasileiro", p. 121/123, item n. 3.1, 13a ed., 2005, Malheiros) - de defendê-lo e de preservá-lo em benefício das presentes e futuras gerações, evitando-se, desse modo, que irrompam, no seio da comunhão social, os graves conflitos intergeneracionais marcados pelo desrespeito ao dever de solidariedade na proteção da integridade desse bem essencial de uso comum de todos quantos compõem o grupo social. (BRASIL. Supremo Tribunal Federal. $>$ http://www.stf.gov.br/jurisprudencia/nova/pesquisa.asp.<).
} 
de prestar contas sobre a administração e a utilização dos bens de uso comum do povo, bem como implica a necessidade de uma maior participação da sociedade na gestão do meio ambiente, já que o povo é o titular do bem ambiental (CIRINO; BASSOLI, 2008).

Assim, Amaral (2007, p. 38) realça que:

[...] o importante é ter presente que o problema ecológico é de natureza econômica e, portanto, o seu tratamento somente se fará com êxito mediante a utilização de instrumentos conaturais ao próprio sistema econômico.

Pleiteando a utilização adequada dos instrumentos tributários e econômico-financeiros para estimular a prevenção de danos ambientais, Yoshida (2005, p. 534) elucida:

[...] a adoção desta estratégia pode contribuir, em muito, para a efetividade da legislação ambiental brasileira, de predominante perfil protetivo-repressivo, bem como para a própria mudança deste clássico perfil legislativo e da forma de controle passivo que lhe é próprio. Este, como se verá, preocupa-se mais em desfavorecer as ações nocivas do que em favorecer as ações vantajosas, sendo nítida a superioridade, em termos de eficácia prática, do controle ativo, que, contrariamente, busca favorecer as ações vantajosas, mais do que desfavorecer as ações nocivas.

A utilização de um olhar ambiental nas políticas econômicas, de fato, tem sido a solução encontrada para uma efetiva contribuição para o desenvolvimento sustentado. E o poder do estado tributador e dos instrumentos tributários na consecução dessas políticas tem sido acentuado como grandes aliados, mormente diante da complexidade dos problemas ambientais que têm sido diagnosticados, por exemplo, em Kioto (AMARAL, 2007, p. 39).

Como agente regulador, visando à proteção do meio ambiente, Jiménez destaca que o Estado tem à disposição instrumentos de duas ordens distintas: os instrumentos normativos e os instrumentos econômicos. Os instrumentos normativos consistem em comandos de controle de emissão ou limitação ao uso de recursos, fiscalização, aplicação de sanção e exigência de reparação do dano (CIRINO; BASSOLI, 2008). A aplicação dos instrumentos normativos na gestão ambiental procura disciplinar o comportamento dos agentes econômicos, impondo ou proibindo determinadas condutas (MODĖ, 2004).

Os instrumentos econômicos visam complementar os mecanismos 
normativos e corrigir, indiretamente, as disfunções ambientais. A sua principal característica consiste na pressão indireta que exercem sobre as atividades poluidoras, influenciando no custo dos bens e serviços. Dentre esses instrumentos destaca-se a tributação ambiental, como eficiente mecanismo econômico capaz de induzir as atividades privadas a adotarem técnicas e produtos menos poluentes. O direito tributário ambiental, por meio da extrafiscalidade, possui nos tributos e nos benefícios fiscais importantes instrumentos na luta contra a degradação do meio ambiente, como será visto adiante.

\section{A EXTRAFISCALIDADE E OS BENEFíCIOS FISCAIS COMO INSTRUMENTOS DE INTERVENÇÃO NO DOMÍNIO ECONÔMICO- AMBIENTAL}

O potencial extrafiscal dos tributos na consecução de comportamentos desejáveis pelo Estado é inconteste. Essa prerrogativa do Estado de intervenção na vida privada se legitima no Estado Democrático de Direito, quando a doutrina incorpora ao conceito de tributo uma dimensão além da obtenção de recursos, ampliando a função desempenhada pelo Direito tributário nas políticas públicas implementadas pelo Estado. Segundo Moro o Direito Tributário, nesse contexto, é reconhecido como um importante instrumento de transformação social, dentro das finalidades contidas na CF. Desse modo, professa o autor a utilização extrafiscal dos tributos como uma exigência constitucional, demarcando as possibilidades de utilização dessas medidas fiscais como instrumentos de intervenção ambiental (GOUVEA, 2006).

Machado (2005) entende que os tributos podem ser classificados em razão de suas três funções: uma fiscal, que corresponde á arrecadação de recursos financeiros para o Estado; uma função extrafiscal apresentando a interferência estatal no domínio econômico; e uma função parafiscal quando o Estado arrecada recursos para atividades que, apesar de não serem funções próprias do Estado, desenvolve por meio de entidades específicas. Para os objetivos deste trabalho, no entanto, as considerações acerca da parafiscalidade não serão objetos de estudo. 
Para os fins a que se destina este estudo, procurar-se-á deter no exame da finalidade extrafiscal dos tributos, pois é nesse campo que se constrói a teoria dos incentivos fiscais que irá ser apresentada.

Apesar de ainda defender-se a ideia de um estado fiscal neutro, com a atividade financeira limitada a fins exclusivamente fiscais, ou seja, a fim de sustentar apenas os serviços públicos indispensáveis á vida coletiva, Becker, citado por Machado Filho (2009), já lecionava sobre o tema, acreditando que essa visão na realidade é uma "distorção histórica". E distingue os resultados que se operam na sociedade pelo tipo de arrecadação tributária priorizada. Assim:

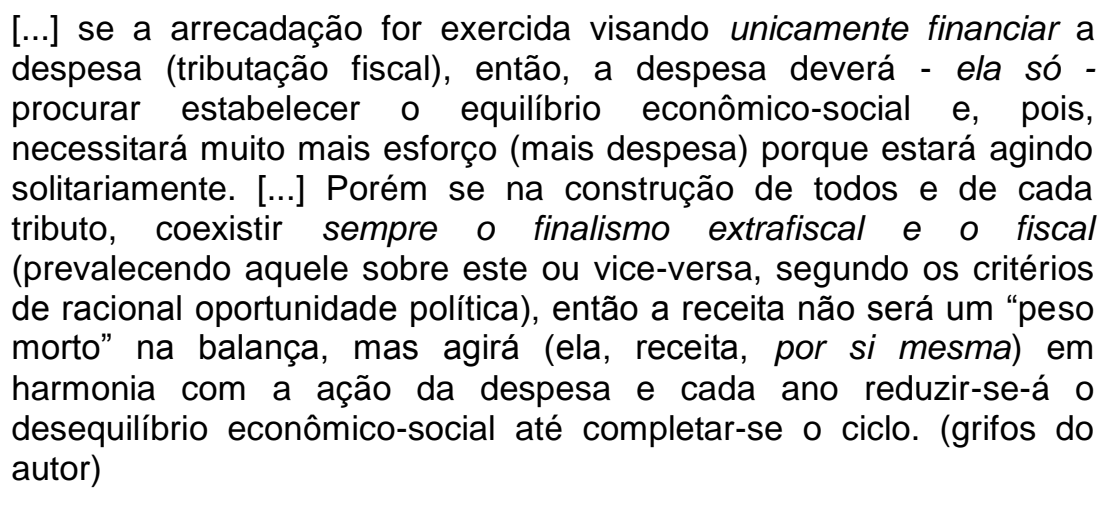

Nesse contexto, Gouvêa (2006) também identifica a estreita relação entre os tributos com finalidades extrafiscais e o Estado regulador ${ }^{6}$. E quando se confronta a questão do desequilíbrio econômico-social com o déficit do meio ambiente, no sentido da falta de um ambiente ecologicamente equilibrado, clareia-se a intrínseca relação entre a melhoria do meio ambiente e a arrecadação tributária, dado que é o orçamento público que financia parte dos custos da recuperação e proteção do meio ambiente degradado pela atividade econômica privada. Assim, a arrecadação tributária advinda dos contribuintes poluidores geralmente não é suficiente para custear a recuperação do meio ambiente que esses mesmos contribuintes causam, o que acaba por agravar 0 déficit do equilíbrio ambiental (REALI, 2006).

Amaro (2001) classifica os tributos conforme os objetivos principais contidos na lei de incidência: arrecadar recursos financeiros (finalidade

\footnotetext{
${ }^{6}$ Ver para uma distinção entre os poderes estatais de regular e de tributar (ELALI, 2007, p. 39).
} 
arrecadatória) ou induzir determinados comportamentos do contribuinte (finalidade regulatória) ${ }^{7}$. Explica Amaro (2001, p. 87):

[...] se a instituição de um tributo visa, precipuamente, a abastecer de recursos os cofres públicos (ou seja, a finalidade da lei é arrecadar), ele se identifica como tributo de finalidade arrecadatória. Se, com a imposição não se deseja arrecadar, mas estimular ou desestimular certos comportamentos, por razões econômicas, sociais, de saúde etc, diz-se que o tributo tem finalidades extrafiscais ou regulatórias. (grifos do autor).

Machado (2006, p. 88) também fornece uma breve diferenciação. Para o autor:

[...] quanto a seu objetivo, o tributo é: a) Fiscal, quando seu principal objetivo é a arrecadação de recursos financeiros para o estado. b) Extrafiscal quando seu objetivo principal é a interferência no domínio econômico, buscando um efeito diverso da simples arrecadação de recursos financeiros [...]. (grifos do autor).

Não obstante a separação conceitual entre a tributação fiscal e a extrafiscal seja, na prática, de difícil realização, e com frequencia as duas finalidades coexistem ${ }^{8}$, apenas com uma análise detalhada da inspiração que cria cada tributo específico e a predominância de sua aplicação, poder-se-ia proceder a tal diferenciação. De fato, entende-se que tanto a tributação fiscal quanto a extrafiscal se prestam para determinados fins sociais, mas a distinção conceitual se faz importante para evidenciar que a extrafiscalidade, segundo Reali (2006, p. 40) pode ser mais objetivamente orientada para o atendimentos de determinados fins, dentre os quais os de natureza ambiental. Dessa forma, pode-se concluir que, assim como a fiscalidade, a extrafiscalidade não existe isoladamente, mas decorre sempre de uma análise da própria norma tributária para sua identificação concreta.

Nessa linha, Gouvêa (2006, p. 12) aduz que a extrafiscalidade "[...] está presente em todo o Direito Tributário, desde os princípios que the informam, passando pelas figuras tributárias, bem como pelos institutos desse ramo do Direito, embora apresente, também, limites [...]". Para o autor, na medida em que a extrafiscalidade está diretamente ligada a valores, e estes estão presentes em todo o ordenamento jurídico, não pode ser considerada como

\footnotetext{
${ }^{7}$ No mesmo sentido MACHADO (2005, p. 72).

${ }^{8}$ Nesse sentido ver MACHADO (2006. p.87).
} 
algo ocasional ou eventual, mas apresenta características inerentes a esses valores.

Essa discussão revela uma visão ampla da tributação, identificada como um "todo unitário" que tem objetivos arrecadatórios ao mesmo tempo em que é capaz de afetar a vida econômica da sociedade. Assim, Gouvêa registra a impossibilidade de diferenciação absoluta entre fiscalidade e extrafiscalidade, pois "[...] tanto a grande estrutura do sistema tributário quanto as medidas fiscais isoladas têm igual preocupação arrecadatória e não arrecadatória [...]" (GOUVEA, 2005, p. 5). Todavia, o autor atribui à extrafiscalidade um conceito:

\begin{abstract}
A extrafiscalidade se constitui no 'algo a mais' que a obtenção de receitas tributárias; liga-se a valores constitucionais; pode ser representada por isenções, benefícios fiscais, progressividade de alíquotas, finalidades especiais, entre outras formas que assume, criando diferenças entre os indivíduos, que são, em última análise, agentes políticos, econômicos e sociais [...] (2006, p. 3).
\end{abstract}

Filia-se o autor, então, aos teóricos que entendem a extrafiscalidade nesta acepção ampla, isto é, entende que ela comporta, além de estímulos e desestímulos a comportamentos, toda arrecadação de tributos que visem a realização de valores, excedendo a mera arrecadação, contudo sem esquecêla. A extrafiscalidade, assim, agregada à fiscalidade, atua finalisticamente e apresenta a dimensão do Direito Tributário que é instrumento de transformação social, capaz de realizar os valores e fins constitucionais.

Nessa ordem de idéias, não se pode ignorar a importância da atuação estatal no exercício de suas funções de ordenar e regular a complexa atividade econômica, visando o desenvolvimento e a justiça social, e o interesse coletivo e público, como bem manda a CF (PIRES 2007).

Cabe apresentar as diversas facetas do instituto da extrafiscalidade, ressaltando o posicionamento de Gouvêa (2006, p. 10):

[...] o princípio ontológico da tributação e epistemológico do Direito Tributário, que justifica juridicamente a atividade tributante do Estado e a impele, com vistas na realização dos fins estatais e dos valores constitucionais, conforme as políticas públicas constitucionalmente estabelecidas, delimitada (a atividade estatal) pelos princípios que revelam as garantias fundamentais do contribuinte.

Operacionalizando uma classificação do fenômeno da extrafiscalidade e 
tendo em vista seu conceito ampliado, este autor fornece uma visão dos seguintes aspectos: os valores constitucionais privilegiados; os aspectos da norma tributária que contém; a interferência no comportamento dos destinatários da norma; e a alteração na carga tributária.

Faz-se necessário, dentro dos objetivos do presente trabalho, identificar esses aspectos na tentativa de demonstrar a estreita relação da extrafiscalidade com a realização dos objetivos constitucionais específicos da proteção ao meio ambiente e da dignidade humana, e de como o Direito Tributário pode contribuir para a realização de uma vida sustentável e digna.

Em primeiro lugar, questionam-se quais os valores que determinam e influenciam a tributação no Estado brasileiro. Sem dúvidas que o Direito Tributário deve obediência à CF. Assim, como não poderia deixar de ser, a extrafiscalidade deve ser usada na realização de todos os objetivos elegidos constitucionalmente que possam ser alcançados mediante a tributação e, consequentemente, afinados com a política fiscal.

Considerando que a CF é repleta na definição de valores e objetivos a serem alcançados, identifica-se um rico conteúdo afeito à realização através da extrafiscalidade.

De uma forma geral, a CF assim lida com a questão dos incentivos fiscais: estabelece as competências tributárias da União, Estados, Distrito Federal e dos Municípios (arts. 153, 155 e 156) e determina que podem conceder isenções os entes políticos que possuem competência para tributar. O artigo 151 veda a instituição de tributo que não seja uniforme em todo território nacional, admitindo a concessão de incentivos fiscais destinados a promover o equilíbrio do desenvolvimento sócio-econômico entre as diferentes regiões do país. Tem-se, também, que qualquer subsídio ou isenção, redução de base de cálculo, concessão de crédito presumido, anistia ou remissão relativos aos tributos somente poderá ser concedido por lei específica, em consonância com o art. 150, § $6^{\circ}$.

Os incentivos estão no campo da extrafiscalidade. Através dos incentivos fiscais a pessoa política tributante estimula os contribuintes a fazerem algo que a ordem jurídica considera conveniente, interessante ou oportuno. Algumas vezes os incentivos fiscais se manifestam através de 
imunidades ou sob a forma de isenções. Tais incentivos somente serão válidos se foram concedidos do exercício ou do não exercício da competência tributária da pessoa política que os concede. A extrafiscalidade também se manifesta pelos desestímulos fiscais, que estimulam contribuintes a não assumirem condutas que, embora lícitas, são consideradas impróprias sob o aspecto político, econômico e/ou social.

Adentrando na questão dos incentivos fiscais ligados a preservação ambiental, Oliveira (2007) acrescenta que a carga tributária diferencial simboliza o reconhecimento estatal da relevância ambiental das decisões pessoais, profissionais ou empresariais dos contribuintes; e para o particular esta representa o incentivo fiscal respectivo.

Pires (2007) destaca que os incentivos fiscais são um tipo de intervenção estatal que se caracteriza por um estímulo de índole econômica para as atividades privadas. Sendo assim, são concedidos para exercerem uma função específica, qual seja, desenvolver ou estimular/desestimular determinada atividade considerada relevante pelo legislador.

Destacando os aspectos mais relevantes, Catão, citado por Pires (2007) propõe uma síntese do conceito de incentivos. Destaca que são instrumentos de desoneração tributária que têm o propósito de estimular determinadas relações jurídicas de índole econômica, concedidos pelo ente político que institui o tributo objeto da concessão do incentivo, com a devida aprovação legislativa.

De outra forma, também podem os incentivos ser classificados de acordo com o âmbito de atuação, se sobre a receita ou sobre a despesa pública, de acordo com o que preceitua o artigo 165 da CF. Não cabe, dada a dimensão do trabalho ora apresentado, conceituar e trabalhar detalhadamente cada tipo de incentivo, pelo que serão objeto apenas de breves comentários.

Sobre a despesa, tem-se a subvenção, o crédito presumido e os subsídios. Do lado da receita, temos a isenção, o diferimento, a remissão e anistia. Os incentivos que operam sobre as despesas públicas seriam, em tese, devido às suas características principais, os que permitem um controle orçamentário mais eficaz. De outra parte, os benefícios sobre a receita, ou as desonerações fiscais, são considerados os benefícios propriamente ditos 
(PIRES, 2007).

Por ora, impele-se a avaliar apenas a relevância da concessão de incentivos fiscais que tenham por mote uma preocupação de ordem ambiental, e de como o Estado pode se utilizar dessa sua prerrogativa para se fazer norteador de comportamentos sustentáveis ecologicamente. Deste modo, não se apega aqui às relações derivadas de cada espécie de incentivo e seus potenciais usos em prol do meio ambiente, mas apenas genericamente a possibilidade de se concedê-los, dada a sua relevância constitucional.

\subsection{A função promocional do Direito}

$\mathrm{Na}$ adoção de políticas públicas tributárias com a finalidade extrafiscal (por meio de instrumentos econômico-financeiros e incentivos tributários) estimuladoras de atividades que auxiliem na busca do desenvolvimento sustentável, Sabbag sugere a utilização da teoria da função promocional do Direito. Para o autor, o Direito Tributário serve para que o governo possa executar sua política. Para corroborar sua tese, cita Becker, para quem:

[...] o Direito Tributário não tem objeto (imperativo econômico-social) próprio; ou melhor, como todo o Direito Positivo, o Direito Tributário tem natureza instrumental e seu 'objetivo próprio' (razão de existir), é ser instrumento a serviço de uma Política. Esta (a Política) é que tem os seus próprios e específicos objetivos econômico-sociais (MACHADO FILHO; SABBAG, 2009).

Essas medidas possuem dupla vantagem: são cabíveis em todas as modalidades de tributos e eliminam o risco latente da utilização do argumento ideológico da preservação ambiental com o fim escuso de ampliar a arrecadação estatal, aumentando em demasia a carga tributária e dificultando as atividades produtivas (NUNES, 2005).

Nesse sentido, elucida Carrazza (2006, p. 665):

[...] deveras, de há muito se percebeu que a lei tributária é melhor (sic) obedecida quando, em lugar de determinar condutas, vale-se do meio mais sutil de influenciá-las, outorgando aos contribuintes subvenções, isenções, créditos presumidos, bonificações etc. Com tal artifício, as pessoas ficam com a sensação de que são livres para conduzir seus negócios e tendem a fazer o que delas a nação espera. 
Também defendendo a tributação promocional com viés ambiental, Yoshida (2005, p. 539) assim se posiciona sobre as técnicas de desestímulo e estímulo às condutas que possam afetar de maneira negativa e positiva, respectivamente, a qualidade do ambiente:

[...] através da técnica de desestímulo, busca-se influenciar o comportamento não desejado (comissivo ou omissivo), obstaculizando-o ou atribuindo-lhe conseqüências desagradáveis; simetricamente, através da técnica de estímulo, busca-se influenciar o comportamento desejado (comissivo ou omissivo), facilitando-o ou atribuindo-Ihe conseqüências agradáveis.

Nabais (2005, p. 425) salienta a importância da função promocional do direito. $E$, como resultado desse entendimento, "[...] há que se assinalar que o segmento mais operacional da extrafiscalidade é, sem sombra para dúvidas, o dos benefícios fiscais [...]". E anota também que eles "[...] constituem um instrumento normal de política econômica e social do estado social contemporâneo [...]" (2005, p. 426).

Através dos benefícios fiscais, se pretende a alteração dos comportamentos humanos. Valendo-se dos incentivos fiscais, podem-se desestimular comportamentos nocivos ao meio ambiente, não através de sanção a ser aplicada aos causadores de degradação, mas utilizando-se da chamada 'sanção premial' para aqueles setores que mudarem as suas atitudes, com a implementação de novas tecnologias, comprometidas com o tipo de desenvolvimento que o Estado quer promover, neste caso, a sustentabilidade ambiental (MACHADO FILHO, 2009).

\subsection{A sanção premial}

Kelsen (1984, p. 49) já deixava transparecer sua posição quanto à inclusão do prêmio no conceito de sanção:

[...] a ordem social pode prescrever uma determinada conduta humana sem ligar à observância ou não observância deste imperativo quaisquer conseqüências. Também pode, porém, estatuir uma determinada conduta humana e, simultaneamente, ligar a essa conduta a concessão de uma vantagem, um prêmio, ou ligar à conduta oposta uma desvantagem, uma pena (no sentido mais amplo da palavra). 
Yoshida (2005) também destaca que estimular comportamentos desejáveis através de técnicas de facilitação ou atribuir prêmios ou incentivos, pode promover mudanças sociais importantes, ao contrário da tradicional função protetivo-repressiva do Estado que, na maioria das vezes não alcança os efeitos desejados.

No mesmo sentido, adiciona Trennepohl (2008, p. 30):

[...] ao fim e ao cabo, a sanção positiva pode ser um elemento objetivo no sentido de estimular condutas $e$ incentivar comportamentos. [...] Basta às normas, previsões de prêmios e recompensas, para atuarem no sentido educativo e preventivo emprestado ao novo modelo de harmonização social, preconizado pelo Estado Moderno.

Para tal desiderato, Muraro, citado por Sabbag (2009) alerta que:

[...] faz-se necessário que o Poder Público incentive esta mudança comportamental, que possa vir a ser implementada através de uma política econômico-social que tenha como instrumento a extrafiscalidade tributária através dos benefícios fiscais, os quais atuarão em conjunto com os princípios de Direito Ambiental, principalmente com o princípio da prevenção, tendo em mente que no caso dos tributos ambientais não está em voga a receita financeira que possa gerar, mas sim o fato sobre o qual venham a incidir. Seriam oferecidos 'prêmios' (benefícios fiscais) para aqueles que não pensarem somente agora, mas nas próximas gerações, na busca do 'desenvolvimento sustentável. (MACHADO FILHO; SABBAG, 2009).

Em sintonia com esta teoria, apresenta-se neste momento, a percepção de alguns autores que identificam nos princípios do direito ambiental presentes na CF as possíveis vantagens desta forma de abordar a relação dos tributos com a promoção do desenvolvimento sustentável.

\subsection{A importância dos instrumentos tributários na proteção ambiental preventiva}

Schoueri (2005) enfatiza que a instituição de tributos ambientais apresenta o efeito indesejado de "monetarização" do Direito Ambiental. Explicase: utilizando-se o tributo com efeito indutor, o contribuinte não é mais visto como alguém que gera danos, mas como alguém que "paga a conta" e, 
portanto, está autorizado a consumir ou usar bens de natureza ambiental. A conseqüência, em médio prazo, registra o autor, seria a diminuição do interesse em evitar práticas danosas ao ambiente, além da própria perda da consciência ambiental.

Salientam-se as vantagens de se prevenir os danos ao meio ambiente, já que são estes, em regra de difícil reparação. Desta forma, os princípios da precaução e da prevenção tomam grande destaque nas discussões acerca da integridade do meio ambiente e, conseqüentemente, à qualidade de vida das presentes e futuras gerações.

Para tanto, temos a contribuição de Yoschida (2005), quando refere que a lógica do poluidor-pagador não tem sido suficiente e efetiva para impedir que a degradação avance e nem para garantir a possibilidade de sua reversão. Cita, como exemplo que têm sido adotadas medidas compensatórias inadequadas pelo Estado, que flexibilizam os custos da reparação do ambiente degradado, e assim, a repressão ao poluidor. No mesmo sentido, Torres (2005) destaca que, dessa forma, poderiam ser estimuladas práticas poluidoras, na medida em que exige-se do poluidor uma simples obrigação patrimonial em contrapartida da poluição que provoca.

Altamirano, citado por Yoshida (2005) reconhece que os benefícios fiscais são mais eficientes para o propósito de proteção ambiental. Os agentes poluidores avaliariam a conveniência de optar por eles quando pudessem viabilizar a realização de seus objetivos comerciais. Nesta tarefa, uma política tributária que objetive minimizar e prevenir os impactos ambientais da atividade econômica deve privilegiar os incentivos econômicos, ao invés de aumentar a carga tributária. Portanto, é melhor incentivar do que penalizar, enfatiza.

Trilhando o mesmo caminho, Carrazza (2006, p. 660) destaca que "[...] a lei tributária é mais bem obedecida quando, em lugar de determinar condutas, vale-se do meio mais sutil de influenciá-las, outorgando aos contribuintes subvenções, isenções, créditos presumidos etc [...]". Assim, enfatiza que ao utilizar o mecanismo da extrafiscalidade para estimular comportamentos dos contribuintes, o Estado quase sempre obtém vantagens maiores do que se previamente arrecadasse os tributos para depois aplicá-los nos gastos públicos. 
É nesse sentido que Ribas (2005, p. 691) pondera:

[...] a concessão de benefícios fiscais, como instrumento de política econômico-social, é legitimada constitucionalmente, mas não pode se dar de forma abusiva e servir ao favorecimento de interesses econômicos de grupos de pressão que exerçam influência ou pertençam às classes dirigentes, sob pena de comprometer a justiça fiscal. Seu manejo há de se dar de forma extraordinariamente prudente, considerando sua indispensabilidade [...]

A extrafiscalidade, incluindo-se aqui os Municípios, transforma-se, então, num importante mecanismo para a atuação do Estado na luta pelo desenvolvimento econômico e ambiental. Esta análise de custo-benefício deverá reger a decisão política do país de conceder ou não os benefícios, sempre em respeito ao orçamento público, à legalidade, a indisponibilidade dos bens públicos, enfim a todos os princípios implícitos e explícitos que regem a ordem econômica, fiscal e ambiental.

\section{CONSIDERAÇÕES FINAIS}

Com relação ao meio ambiente, muito se tem discutido e pensado a respeito das formas de barrar sua degradação, ao mesmo tempo em que se vê sua total inadequação ao sistema capitalista brasileiro, que é baseado no consumo. A questão que se coloca é: como compatibilizar a incitação ao consumo de bens e serviços e tecnologias, com a sustentabilidade e com a necessidade de se utilizar de forma diferenciada os recursos ambientais.

Conclui-se que a educação, a par de seu indubitável papel transformador da sociedade, sozinha não basta para se chegar a diminuição do consumo a padrões aceitáveis de sustentabilidade. Há a necessidade de se utilizar de instrumentos mais efetivos e que mexam diretamente no "bolso" dos agentes sociais, políticos e econômicos. Há que se enfrentar a questão da necessidade de proteção ambiental com as mesmas armas que autorizam a poluição desenfreada: o alvo deve ser o lucro. Por isso, acredita-se nos instrumentos tributários como forma de direcionar o comportamento dos homens e dos agentes econômicos que são responsáveis pelo desenvolvimento. 
Embora exista no ordenamento jurídico brasileiro uma excelente previsão acerca da proteção do meio ambiente, calcada no artigo 225 da CF para que esse direito fundamental seja materializado é preciso que o Poder Púbico e a coletividade cumpram com os deveres fundamentais inerentes a esse direito. E para tanto, é necessário modificar a atual racionalidade reducionista e instrumental que dirige as atividades econômicas e os padrões de consumo. O homem precisa visualizar-se dentro do conceito de meio ambiente. Da mesma forma, a economia não pode ser separada do meio ambiente, por isso que as decisões econômicas devem considerar seus impactos sobre a natureza. A relação entre a pobreza e os problemas sociais não deve ser menosprezada. Problemas ecológicos e sociais estão fortemente interligados e se reforçam mutuamente.

A questão, a despeito de sua complexidade, não pode ser irrelevada. $O$ enfrentamento se faz necessário e premente, mormente diante da imensa crise ecológica global que atormenta todos os indivíduos e povos. Como bem prevê a CF, a competência sobre as questões do Meio Ambiente perpassam todos os entes federados, e deles são, ao mesmo tempo, as responsabilidades por suas ações ou omissões. Ademais, à coletividade, à sociedade civil, também é atribuída a competência e a obrigação de agir em prol da sustentabilidade, na medida de suas responsabilidades para com sua geração e com as futuras.

Por todo o exposto, considera-se, neste estudo, que quaisquer embargos a utilização da extrafiscalidade tributária, no seu apropriado instituto dos incentivos fiscais, deve ser revista e repensada à luz dos propósitos e mandamentos da Constituição. E essa, por sua vez, estabelece o dever do Estado de se utilizar de todos os instrumentos que se mostrarem eficazes na busca de uma vida digna para todos os indivíduos. Coaduna-se, portanto, o mandamento constitucional com a utilização dos instrumentos fiscaistributários, que se apresentam como eficazes indutores de comportamentos economicamente direcionados, o que é essencial quando se trata de compatibilizar o desenvolvimento econômico com a sustentável utilização dos recursos ambientais.

Daí a enorme importância em se discutir as políticas tributárias e ambientais e de lhes procurar dar mais efetividade e eficácia. Esse é o 
entendimento que deve ser colocado na ordem do dia das discussões acerca da aplicação do Direito. Essas considerações não podem ser apartadas das decisões jurídicas.

Por fim, em síntese, o artigo pretendeu defender que 0 interesse arrecadatório do Brasil, no presente caso, deve ser mitigado em prol do interesse público maior da proteção ambiental, pois a própria viabilidade da vida humana no planeta depende de ações positivas do Estado, nesse sentido lembrando que os Municípios, como já dito, são entes estatais, republicanos e federados, cabendo a eles, nos limites de suas autonomias, o mesmo compromisso dado aos demais entes federados.

\section{REFERÊNCIAS}

AMARAL, Paulo Henrique. Direito tributário ambiental. São Paulo: RT, 2007.

AMARO, Luciano. Direito tributário brasileiro. 6. ed. São Paulo: Saraiva, 2001.

BRASIL. Constituição (1988). Constituição da República Federativa do Brasil.

Brasília, DF: Senado Federal, 1988. Disponível em: <http://www.planalto.gov.br/ccivil_03/Constituicao/Constituiçao.htm> Acesso em: 13 maio 2010.

CARRAZZA. Roque Antônio. Curso de direito constitucional tributário. 22. ed. São Paulo: Malheiros, 2006.

CIRINO, Samia Moda; BASSOLI, Marlene Kempfer. Direito tributário ambiental: benefícios fiscais às empresas para proteção do direito fundamental ao meio ambiente. Scientia iuris, Londrina v. 12, p. 177-198, 2008. Disponível em: $<$ www.uel.br/revistas/uel/index.php/iuris/article/view/4168/3619>. Acesso em: 10 maio 2010.

ELALI, André. Incentivos fiscais, neutralidade da tributação e desenvolvimento econômico: a questão da redução das desigualdades regionais e sociais. In: MARTINS, Ives Granda; ELALI, André; PEIXOTO, Marcelo M. (Coord.). Incentivos fiscais. questões pontuais nas esferas federal, estadual e municipal. São Paulo, MP Ed., 2007.

FIGUEIREDO, Marcelo. A constituição e o meio ambiente: - os princípios constitucionais aplicáveis a matéria e alguns temas correlatos. In: TÔRRES, Heleno Taveira (Org.). Direito tributário ambiental. São Paulo: Malheiros, 2005.

FIORILLO, Celso A. P.; FERREIRA, Renata M. Direito ambiental tributário. 2. 
ed. São Paulo: Saraiva, 2009.

GOUVEA, Marcus de Freitas. A extrafiscalidade no direito tributário. Belo Horizonte: Del Rey, 2006.

GRAU, Eros Roberto. A ordem econômica na Constituição de 1988. 7. ed. São Paulo: Malheiros, 2002.

KELSEN, Hans. Teoria pura do direito. 6. ed. Coimbra: Arménio Amado Ed., 1984.

LEAL, Monia Hennig. Constituição como princípio: os limites da jurisdição constitucional brasileira. Barueri, S.P.: Manole, 2003.

MACHADO, Hugo de Brito. Curso de direito tributário. 26. ed. São Paulo: Malheiros, 2005.

MACHADO FILHO, Haroldo e SABBAG, Bruno K. Classificação da natureza jurídica do crédito de carbono e defesa da isenção tributária total às receitas decorrentes da cessão de créditos de carbono como forma de aprimorar o combate ao aquecimento global. Disponível em: $<$ http://www.buscalegis.ufsc.br/revistas/files/journals/2/articles/32148/public/321 48-38095-1-PB.pdf>. Acesso em: 13 nov. 2009.

MELLO, Celso de. ADI 3540 MC. Julgado em 01/09/2005. DJ 03/02/2006. Disponível em: <http//www.stf.jus.br>. Acesso em: 10 maio 2010.

MODÉ, Fernando Magalhães. Tributação ambiental: a função do tributo na proteção do meio ambiente. Curitiba: Juruá, 2004.

NABAIS, José Casalta. Direito fiscal e tutela do ambiente em Portugal. In: TÔRRES, Heleno Taveira (Org.). Direito tributário ambiental. São Paulo: Malheiros, 2005.

NUNES, Cleucio Santos. Direito tributário e meio ambiente. São Paulo: Dialética, 2005.

OLIVEIRA, Jose Marques Domingues. Direito tributário e meio ambiente. 3. ed. Rio de Janeiro: Forense, 2007.

PIRES, Adilson Rodrigues. Ligeiras reflexões sobre a questão dos incentivos fiscais no Brasil. In: MARTINS, I. G.; ELALI, A.; PEIXOTO, M. (Coord.). Incentivos fiscais. Questões pontuais nas esferas federal, estadual e municipal. São Paulo: MP Ed., 2007.

REALI, Darci. Os municípios e a tributação ambiental. Caxias do Sul: EDUCS, 2006. 
RIBAS, Lídia Maria Lopes Rodrigues. Defesa Ambiental: utilização de Instrumentos Tributários. In TÔRRES, Heleno Taveira (Org.). Direito Tributário Ambiental. São Paulo: Malheiros, 2005.

RODRIGUES, Hugo Thamir; FREITAS, Daniel Dottes de. Cooperativismo interinstitucional público: uma proposta de gestão pública tributária para superação da guerra fiscal em busca do desenvolvimento. Direitos sociais \& Políticas públicas: desafios contemporâneos, Santa Cruz do Sul: Editora da UNISC, tomo 9, p. 2686-2705, 2009.

RODRIGUES, Hugo Thamir; DANELI FILHO, Eloi Cesar. República e tributação solidária: caminho em direção de uma cidadania politicamente ativa para 0 século XXI. Direitos sociais \& Políticas públicas: desafios contemporâneos, Santa Cruz do Sul: Editora da UNISC, tomo 10, p. 3055-3085, 2010.

SILVA, José Afonso da. Direito ambiental constitucional. 6. ed. São Paulo: Malheiros, 2007.

TRENNEPOHL, Terence Dornelles. Incentivos fiscais no direito ambiental. São Paulo: Saraiva, 2008.

TÔRRES, Heleno Taveira. Da relação entre competências constitucionais tributária e ambiental - os limites dos chamados "tributos ambientais". In: TÔRRES, Heleno Taveira (Org.). Direito tributário ambiental. São Paulo: Malheiros, 2005.

TUPIASSU, Lise Vieira da Costa. Tributação ambiental: a utilização de instrumentos econômicos e fiscais na implementação do direito ao meio ambiente saudável. Rio de Janeiro: Renovar, 2006.

YOSHIDA, Consuelo. A efetividade e a eficiência ambiental dos instrumentos econômico-financeiros e tributários. Ênfase na prevenção. A utilização econômica dos bens ambientais e suas implicações. In: TÔRRES, Heleno Taveira (Org.). Direito tributário ambiental. São Paulo: Malheiros, 2005.

Recebido para publicação: 04/12/2012

Aceito para publicação: 19/12/2012 